\section{Dream-based cartography: creative processes involving an imaginary Prague}

\section{Andréa Catrópa}

\section{Universidade Anhembi Morumbi}

This work aims to discuss aspects of artistic creation derived from dream speculation. Based on a dream that took place in the capital of Czechoslovakia, a region unknown to the dreamer, and which happened at the beginning of the quarantine period due to the Coronavirus pandemic, the research began on the internet using search mechanisms. In the evening event, in addition to its narrative elements, the journey through places that presented themselves vividly was of paramount importance, so the first stage arose from the researcher's curiosity in verifying if there was any coincidence between the real Prague and the dream Prague. To her surprise, although there was no prior contact with systematized information about that location, coincidences were emerging. And these similarities allowed the initial elaboration of a data collection for the memories would not be lost and could be used in the future as tools for artistic creation. Somehow, that fact so unique and different from other experienced dream phenomena aroused a series of sensations and reflections on the possibility of incorporating the unforeseen and irrational element, which daily invades our senses when we are asleep, as a means of promoting academic inquiry and artistic research.

In Antiquity, as the work of Artemidoro confirms, the dream had a cosmic dimension that was related to the mystical tradition and to the collectivity. However, the psychoanalytic conception, influential in western society since the first decades of the twentieth century, contributed to fixing the perception of the dream as a private event and that concerns only the individual dimension. At the same time, neuroscience favors a biological approach to dreaming, even though Sidarta Ribeiro is a dissonant voice in this environment and dedicates himself to research focused on the "oracle of the night". The Brazilian neuroscientist says that, in his work, he identified a very intricate relationship between dreams and memory and a double temporal articulation: we dream as a way of remembering what we are and do, and also to prepare for the future.
These reflections joined the coordinates collected by me during the aforementioned night experience. The conceptual project design that I provisionally called "Prague Dreamiary" started from a dream and proceeded, at first, with the help of Internet search engines. From there, a map was created that unites both objective information found on the networks and the translation of dreamed symbolic messages. The dream experience allowed a deviation in the search algorithms by means of private intuition, which contradicts the consensual rational tendency behind the "improvement" of the artificial intelligence of these mechanisms. In addition to the creation of "dream hyperlinks", this process included bibliographic research and the creation of a digital banner for the online page that will contain more information about the work in process.

\section{KEYWORDS}

Art \& Design, Creative process, Dream-based experience,

Interdisciplinary research, Search Algorithms 